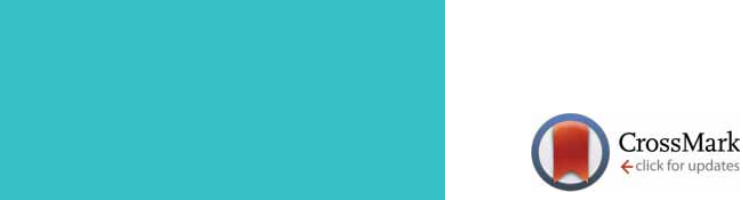

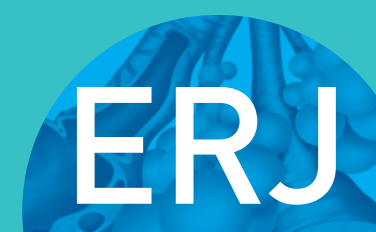

open research
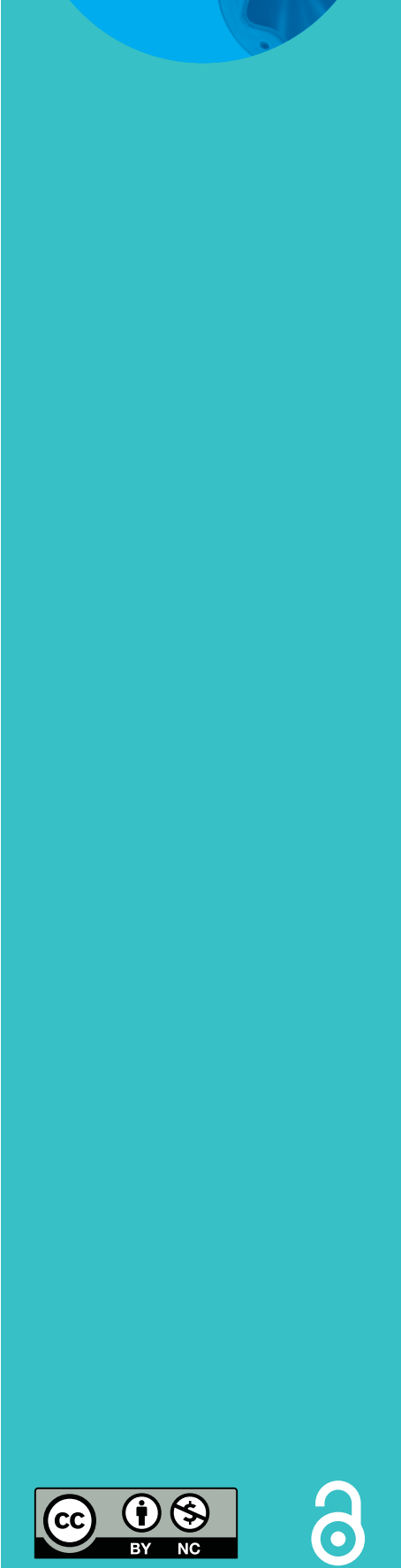

\section{Noninvasive ventilation in stable hypercapnic COPD: what is the evidence?}

\author{
Marieke L. Duiverman ${ }^{1,2}$
}

Affiliations: 'Dept of Pulmonary Diseases/Home Mechanical Ventilation, University of Groningen, University Medical Center Groningen, Groningen, The Netherlands. ${ }^{2}$ Groningen Research Institute of Asthma and COPD, University of Groningen, Groningen, The Netherlands.

Correspondence: M.L. Duiverman, University Medical Center Groningen, Postbox 30.001, 9700 RB Groningen, The Netherlands. E-mail: m.l.duivermandumcg.nl

ABSTRACT Long-term noninvasive ventilation (NIV) to treat chronic hypercapnic respiratory failure is still controversial in severe chronic obstructive pulmonary disease (COPD) patients. However, with the introduction of high-intensity NIV, important benefits from this therapy have also been shown in COPD. In this review, the focus will be on the arguments for long-term NIV at home in patients with COPD. The rise of (high-intensity) NIV in COPD and the randomised controlled trials showing positive effects with this mode of ventilation will be discussed. Finally, the challenges that might be encountered (both in clinical practice and in research) in further optimising this therapy, monitoring and following patients, and selecting the patients who might benefit most will be reviewed.

@ERSpublications

Adequately set chronic NIV improves outcomes in COPD patients with severe chronic hypercapnic respiratory failure http://ow.ly/slW230i8lck

Cite this article as: Duiverman ML. Noninvasive ventilation in stable hypercapnic COPD: what is the evidence? ERJ Open Res 2018; 4: 00012-2018 [https://doi.org/10.1183/23120541.00012-2018].

Received: Jan 192018 | Accepted: Jan 272018

Conflict of interest: M.L. Duiverman reports receiving grants from Philips/Respironics, RESMED and Vivisol, and personal fees from Novartis outside the submitted work.

Copyright $\odot$ ERS 2018. This article is open access and distributed under the terms of the Creative Commons Attribution Non-Commercial Licence 4.0. 


\section{Introduction}

Chronic obstructive pulmonary disease (COPD) is a disease with high mortality and morbidity worldwide [1]. Patients with end-stage COPD frequently develop chronic hypercapnic respiratory failure (CHRF) associated with end-of-life. In this stage of disease, patients experience extremely disabling symptoms of dyspnoea, leading to severely impaired health-related quality of life (HRQoL), with limited treatment options.

Long-term nocturnal noninvasive ventilation (NIV) has been applied in patients with chronic alveolar hypoventilation for decades. While there is no doubt that applying chronic nocturnal NIV improves outcomes in patients with restrictive and neuromuscular diseases [2-4], there has been conflicting evidence for its benefits in COPD patients for a long period [5-15]. This has led to enormous variety in the application of long-term NIV in COPD throughout Europe [16]. However, with the introduction of high-intensity NIV (HI-NIV), important benefits have been shown [17-20] and the discussion about NIV in COPD has changed. Nevertheless, despite these positive findings, the application of long-term NIV in patients with severe COPD should be considered carefully, as knowledge gaps remain with regard to patient selection, the optimal place to initiate NIV and the optimal ventilatory settings to be used.

In this review, the focus will be on the arguments for long-term NIV at home in patients with COPD. The evolution of (high-intensity) NIV in COPD and the randomised controlled trials (RCTs) showing positive effects with this mode of ventilation will be discussed. Furthermore, the challenges that might be encountered (both in clinical practice and in research) in further optimising this therapy and selecting the patients who benefit most will be reviewed.

\section{The history of high-intensity noninvasive ventilation}

The first reports of NIV in stable severe COPD date from the 1980s. During this period, negative pressure ventilation using a cuirass or poncho warp ventilator was the most widely used ventilatory mode. These first studies on negative pressure ventilation in stable severe COPD showed variable results, with some smaller trials showing a positive effect on gas exchange, respiratory muscle strength, hospitalisation rates, or dyspnoea [21-26] and some, including a large RCT, showing no benefit at all [27, 28]. Furthermore, almost all studies concluded that there was poor patient tolerance for long-term use of negative pressure ventilation [28].

In the mid-1980s, positive pressure ventilation became more widely available. It was expected that this mode would improve tolerance and outcomes. However, in contrast to the situation in neuromuscular or restrictive thoracic diseases, in which positive pressure ventilation gained more and more popularity, the benefits of this more easily tolerable mode of ventilation were still not demonstrated unambiguously in COPD. Although the first positive pressure ventilation trials were small [12] or uncontrolled, trials including more patients and a randomised design also did not show any (or only very limited) benefits in gas exchange, lung function, symptoms or $\operatorname{HRQoL}[5,6,8,9,11-13]$.

\section{Randomised controlled trials using high-intensity noninvasive ventilation}

More than 15 years ago, the concept of HI-NIV was introduced by WINDISCH et al. [18]. Considering the studies performed prior to that time $[5,6,8,9,12,13]$ they concluded that most used inadequate ventilatory settings with which no effect on ventilation and gas exchange could have been expected in severe COPD patients. One of the first reports pinpointing this problem was that by MEECHAM Jones et al. [10], in which they showed that with a moderate inspiratory airway pressure (IPAP) of $18 \mathrm{cmH}_{2} \mathrm{O}$, nocturnal gas exchange improved. This improvement in nocturnal gas exchange correlated with daytime improvements in gas exchange and so it was hypothesised that to achieve any benefit in gas exchange and other patient centred outcomes, one first had to be sure that effective ventilation was achieved.

The Windisch group started to ventilate their COPD patients with high inspiratory pressures and a high back-up respiratory rate (BURR). They first reported on their outcomes in a retrospective cohort $[18,19]$ and, although these data were uncontrolled and retrospective and there was surely a patient selection bias, the amount of improvement in gas exchange, lung function and HRQoL was impressive. To confirm those results, they set-up a randomised cross-over trial in which they showed that HI-NIV improved gas exchange and HRQoL as compared to the previously used "low-intensity" NIV settings [17]. However, the settings used in these studies were extremely high when compared to previous and a lot of caregivers were concerned about compliance with them. Although the Windisch group started to redefine HI-NIV as "...The concept of using higher IPAP levels in addition to controlled ventilation aiming for maximal $\mathrm{PaCO}_{2}$ reduction..." [29] and showed that compliance and sleep quality were not worse with HI-NIV and could even be better when compared to low-intensity NIV (LI-NIV) [30, 31], in real life it remained difficult to achieve the HI-NIV goals in all patients. Patient tolerance with this setting often limits the range in which IPAP and BURR can be increased. 
Unfortunately, we lack knowledge about what HI-NIV is actually doing with the respiratory system and why it is sometimes difficult to get patients to adjust to it (patients certainly need more time to get used to HI-NIV, leading to more hospitalisation days [17, 32]). Furthermore, while the concept of HI-NIV seemed to be rather effective, parallel-group RCTs were needed which showed the feasibility and clinical benefits of this mode in real-life situations. Until now, three larger randomised controlled studies [33-35] have been published that show important benefits of HI-NIV in severe COPD. Of particular note is the fact that these studies were performed under different circumstances. Moreover, the negative RESCUE trial shows no effect of HI-NIV in a cohort of patients that continued HI-NIV after an exacerbation [36]. Figure 1 illustrates the development of ventilatory settings over time and the studies in which these settings are used. The RCTs using HI-NIV and the RESCUE trial will be discussed extensively in the following sections.

Noninvasive ventilation as an addition to pulmonary rehabilitation in severe stable COPD

Pulmonary rehabilitation is a well proven effective treatment to improve HRQoL, relieve dyspnoea, reduce exacerbations and improve self-management in patients with symptomatic COPD of any stage [1]. It is also effective in patients with severe COPD but might be problematic to fulfil as patients experience disabling symptoms of dyspnoea and lowering of energy levels. In 2011, the results of the RECOVER trial were published where it was investigated whether, in stable severe COPD, the addition of NIV to a multidisciplinary pulmonary rehabilitation programme would improve outcomes as compared to pulmonary rehabilitation alone $[33,37]$. In this study, a ventilatory strategy was used in which the aim was to achieve normocapnia during daytime by increasing IPAP and BURR. Eventually, after a quite intensive investment in optimal NIV titration (mean hospitalisation 7 days, including 2 arterial blood gas recordings in the intensive care unit), patients were ventilated with a mean IPAP of $24 \mathrm{~cm} \mathrm{H}_{2} \mathrm{O}$ and a BURR of 18 breaths $\mathrm{min}^{-1}$. Only three out of 31 patients randomised to the NIV+pulmonary rehabilitation group dropped out because of intolerance to the therapy. With this strategy we showed that, in patients with moderate CHRF (mean arterial carbon dioxide tension $\left(\mathrm{PaCO}_{2}\right)$ at baseline $6.8 \mathrm{kPa}$ ), adding NIV improved HRQoL and dyspnoea, and, of particular note, stabilised or even improved forced expiratory volume in $1 \mathrm{~s}$ (FEV1) over the complete study period of 2 years (figure 2). In fact, patients on NIV were far better equipped to maintain the improvement they achieved during the first 12-week inpatient rehabilitation programme during the 21 months of outpatient rehabilitation afterwards.

\section{Noninvasive ventilation as an addition to standard care in severe stable COPD}

KöHNLEIN et al. [34] showed in a large RCT that treating COPD patients suffering from severe CHRF with NIV impressively improves survival. 195 patients with very severe CHRF in stable condition were randomised either for addition of NIV to their standard therapy (in all patients this included long-term oxygen therapy but not pulmonary rehabilitation) or standard therapy alone. Patients were included from

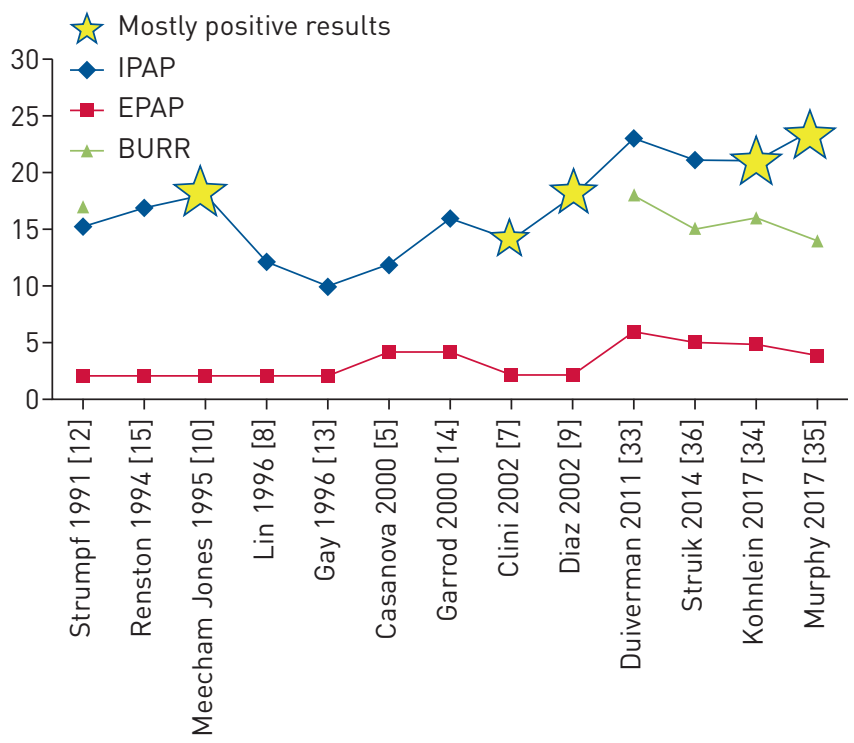

FIGURE 1 Evolution of ventilatory settings in randomised controlled trials investigating noninvasive ventilation in stable or post-exacerbation chronic obstructive pulmonary disease. IPAP: inspiratory airway pressure; EPAP: expiratory airway pressure; BURR: back-up respiratory rate. 


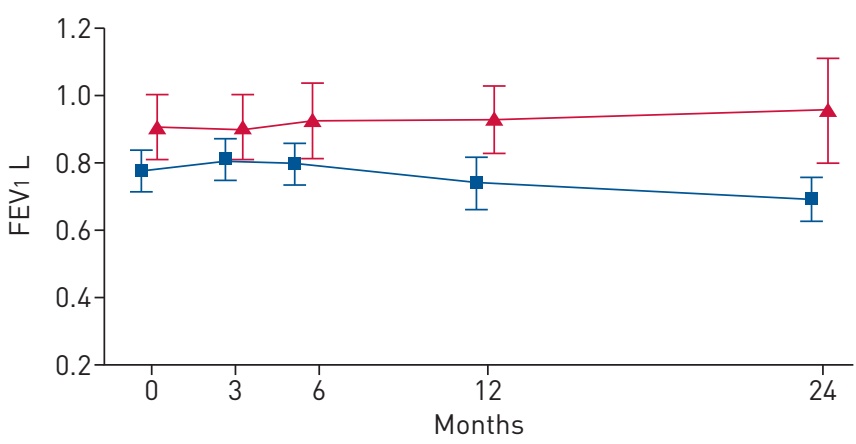

FIGURE 2 Forced expiratory volume in $1 \mathrm{~s}$ (FEV 1 ) results in the RECOVER trial. FEV 1 was measured at different points for the noninvasive intermittent positive pressure ventilation (NIPPV) + rehabilitation group (red triangles) and the rehabilitation group (blue squares). The change was significantly better in the NIPPV + rehabilitation group $(p<0.02)$. Reproduced from [33] with permission from the publisher.

36 hospitals throughout Germany and Austria and these hospitals were instructed to ventilate with a high-intensity approach, aiming at a reduction in daytime $\mathrm{PaCO}_{2}$ of at least $20 \%$. To achieve this, patients were hospitalised for a mean of 5.6 days. Eventually, patients ended up with a mean IPAP of $21.6 \mathrm{cmH}_{2} \mathrm{O}$ and a mean BURR of 16 breaths min $^{-1}$. Adding NIV to standard care improved survival from $77 \%$ in the standard care group to $88 \%$ in the NIV+standard care group. Of note, it seems that this survival benefit was achieved immediately after initiation of NIV, a period in which patients with this degree of CHRF (mean $\mathrm{PaCO}_{2} 7.8 \mathrm{kPa}$ at baseline) are probably extremely vulnerable. Furthermore, besides benefits in gas exchange, FEV1, exercise tolerance and HRQoL were also improved.

\section{Noninvasive ventilation after severe exacerbations}

Patients who become respiratory insufficient due to a COPD exacerbation and need invasive or noninvasive mechanical ventilation for the acute event have a very poor prognosis after hospital discharge [38-42]. More than $60 \%$ of these patients are readmitted and more than $25 \%$ die within the first year after discharge [39]. Therefore, the thought that continuation of NIV at home after discharge might be helpful is quite attractive. MurPhy et al. [35] recently showed that when you initiate NIV in patients that remain severely hypercapnic after an exacerbation, hospital readmissions are delayed and reduced. This study was also an important landmark in the NIV field, as this important benefit was achieved not only through adequate ventilatory settings (mean IPAP $24 \mathrm{cmH}_{2} \mathrm{O}$, mean BURR 14 breaths $\mathrm{min}^{-1}$ ) but also through very careful patient selection (only patients that had still a daytime $\mathrm{PaCO}_{2}>7.5 \mathrm{kPa} 2-4$ weeks after discharge from the index hospital admission were included). However, it might be possible that a substantial proportion of chronic hypercapnic patients were included that were already hypercapnic before the index hospital admission, a group for which it was already known that NIV was of benefit. In addition, patients that were unable to tolerate NIV during the index hospital admission were excluded. This patient selection might explain the differential result as compared to the RESCUE trial by STRUIK et al. [36]. In the latter, 201 patients were included that were moderately hypercapnic $48 \mathrm{~h}$ after weaning from NIV or invasive mechanical ventilation and randomised to NIV or standard care to be continued for a year. This study did not show any benefit at all despite the use of HI-NIV (mean IPAP $19 \mathrm{cmH}_{2} \mathrm{O}$, mean BURR 5 breaths $\min ^{-1}$ ), probably because many patients in the control group showed spontaneous recovery in their $\mathrm{PaCO}_{2}$.

\section{Noninvasive ventilation in COPD}

Four larger well-designed RCTs have been performed using HI-NIV in patients with severe COPD [33, 34, $36,43]$. In stable chronic hypercapnic patients, two studies showed quite convincing benefits although a survival benefit was only shown in one study (level B evidence) $[33,34]$. In patients in whom NIV was initiated, or in whom it was continued after an exacerbation with acute respiratory failure, evidence is mixed; however, is seems that when you select patients that remain hypercapnic, important benefits with regard to rehospitalisation can be achieved (level B evidence) [43]. Nevertheless, from these studies it becomes clear that challenges have to be overcome with regard to patient selection, the timing of NIV and the optimal (HI)-NIV settings to be used.

\section{Challenges in noninvasive ventilation}

\section{Patient selection and outcomes}

NIV is most convincingly of benefit in COPD patients with CHRF in a stable condition [33, 34]. Patients with very severe hypercapnia seem to benefit more, at least with respect to gas exchange benefits (this might be "regression to the mean") but also regarding survival benefits. However, what we consider as the 
most important outcome parameter remains an interesting discussion. In fact, patients usually care most about their quality of life (QoL), might care about survival (with good QoL), but usually do not care about $\mathrm{PaCO}_{2}$ changes. Furthermore, although some studies have shown that hypercapnia is associated with a worse prognosis [44-46], it is unclear whether NIV-induced changes in $\mathrm{PaCO}_{2}$ influence HRQoL or survival. BUDWEISER et al. [46] showed that patients with a base excess of $>9 \mathrm{mmol} \cdot \mathrm{L}^{-1}$ might improve their survival once this is lowered by NIV; however, such a base excess of $9 \mathrm{mmol} \cdot \mathrm{L}^{-1}$ represents an extreme CHRF state, much worse than that in the Köhnlein trial. For patients with moderate CHRF this relationship has not been shown; moreover, for HRQoL there seems to be no relationship with $\mathrm{PaCO}_{2}$. This means that the positive effects of NIV reach beyond solely an improvement in gas exchange and, maybe, that improvements in HRQoL might themselves improve survival [47]. Important HRQoL benefits have also been shown in moderate hypercapnic patients [33,37]. It has been hypothesised that NIV facilitates a more active way of living and therefore a better ability of patients to work on their general life style. Indeed, it has been shown that positive effects can be obtained when you combine NIV with pulmonary rehabilitation [33]. In severely hypercapnic COPD patients, studies show only small benefits in HRQoL, probably because HRQoL is influenced by many other factors, such as a poor general condition or comorbidities, which tend to be more prevalent in patients with more severe COPD.

In patients that exacerbate frequently the benefits of NIV are less certain. Despite MurPHy et al. [35] showing that NIV might increase the time to readmission and rehospitalisation, effects on HRQoL were disappointing. In this study, only patients that remained severely hypercapnic (who were probably already chronically hypercapnic before the index exacerbation) were included and these patients probably benefit in terms of readmission risk. It should be noted, however, that the reduction of hospitalisation rates does not apply for patients that recover faster, as has been shown by STRUik et al. [11]. Also, it is unclear which group of patients benefit from a reduction in readmissions and exacerbations and at the same time an improved HRQoL.

\section{Optimal settings to be applied}

HI-NIV, defined as "...the concept of using higher IPAP levels than used in most of the older RCTs in addition to controlled ventilation aiming for maximal $\mathrm{PaCO}_{2}$ reduction..." [29], is the preferential mode of ventilation in COPD. Benefits have been shown with this mode; however, this definition is quite vague and positive and potential negative effects of HI-NIV have only been investigated in limited fashion. Furthermore, in clinical practice, increasing IPAP and BURR might lead to patient discomfort. Increasing our knowledge about the mechanisms of HI-NIV and how we should adjust our settings most adequately to act upon potential negative factors will improve ventilatory efficacy, patient tolerance and eventually outcomes.

\section{Understanding the mechanisms involved}

As per the definition above, HI-NIV improves arterial blood gases and this improved gas exchange has positive effects on certain symptoms, such as morning headache. Nevertheless it is unknown by which mechanisms 1) arterial blood gases are improved and 2) other (patient-centered) outcomes, such as HRQoL and survival, are improved. Why HI-NIV works remains a "black box" and the relationship between an improvement in gas exchange and other outcomes is not as clear as it may seem.

WINDISCH et al. [20] showed in one of their first studies that HI-NIV is able to improve breathing patterns. This improved breathing pattern, with higher tidal volumes, lower breathing frequencies and higher minute ventilation, can be maintained during the day, possibly as a consequence of a change in respiratory drive or improved pulmonary mechanics because of a decrease in hyperinflation. The hypothesis that NIV improves respiratory drive has only been investigated in two small trials, as follows: 1) ElLIOT et al. [48] showed that the change in $\mathrm{PaCO}_{2}$ in 12 stable COPD patients correlated with the increase in ventilation during a rebreathing manoeuvre (at an end-tidal $\mathrm{CO}_{2}$ value of $8 \mathrm{kPa}$ ), and 2) NicKOL et al. [49] showed findings of improved chemosensitivity as a reason for improved ventilation and thus gas exchange.

While this might be an attractive explanation for patients that show depressed respiratory drive, COPD patients with a small breathing reserve and a high respiratory drive, who are breathing close to the fatigue threshold, might need additional mechanisms in order to enable them to increase their ventilation in response to a certain level of increased $\mathrm{PaCO}_{2}$. In this respect it is attractive to search for changes in lung function, i.e. airway obstruction and/or hyperinflation, as a way to unload the heavily loaded respiratory system in COPD. That NIV is able to decrease hyperinflation was shown by DiAz et al. [50], who showed impressive improvements in residual volume and intrinsic positive end-expiratory pressure with short periods of daytime NIV. Also, the mechanistic studies of Elliot and Nickol showed effects on hyperinflation parameters. Unfortunately, lung volumes were seldom investigated in longer-term nocturnal studies. 
An interesting finding in the high-intensity trials is that NIV seems to be able to stabilise FEV1 [17, 19, 33, 34], meaning that NIV directly affects airway characteristics. First, it might be that NIV, as it dilates airways at least a couple of hours during the day, opposes bronchoconstriction-induced effects on the airways. It is known that mechanical forces occurring in the airway as a consequence of bronchoconstriction are sufficient to not just induce symptoms but also to influence airway biology [51-53]. On the other hand, it is known that therapies such as mechanical ventilation and prevention of vagally-induced airway narrowing by targeted lung denervation have positive effects on airways [54]. Furthermore, patients with chronic hypercapnia are known to retain fluid because the renin-angiotensin-aldosterone system (RAAS) is activated. This excess fluid might be retained in the airway wall and, if hypercapnia is reduced, oedema might decrease and airway dilation might occur. However, it is completely unknown how NIV acts on airway characteristics, as these studies are quite complex to perform in patients with severe COPD. Interestingly, complex studies have shown that airflow redistribution into the lungs may change on NIV, thereby improving ventilation-perfusion matching $[55,56]$.

A long-standing hypothesis is that NIV rests overloaded fatigued respiratory muscles [57]. In fact, it is questionable as to whether the respiratory muscles are fatigued, as several reports support the hypothesis that chronic hypercapnic COPD patients adopt a pattern of rapid shallow breathing to prevent the muscles becoming fatigued [58-60]. This would mean that patients act as "wise fighters", not pushing their probably weaker [61] muscles to the limits. Furthermore, it is known that the diaphragm of these patients adapts to the chronic overload by developing more fatigue resistant Type I fibres [62]. Also, studies of NIV do not provide us with much evidence that the respiratory muscles are rested [63]. Notably, the methods by which this phenomenon was assessed were differential and it should be noted that maximal inspiratory pressure measurements in particular do not reflect muscle fatigue adequately [64]. Nevertheless, while the diaphragm might not be fatigued, it is known that all kinds of cellular and molecular alterations occur that reduce the force generating capacity of diaphragm muscle fibers [61, 62]. Therefore, it might still be possible that respiratory muscle rest or recovery contribute to the improved balance between capacity/drive and respiratory system load, leading to improved breathing patterns and gas exchange.

Finally, in addition to these direct effects augmenting (alveolar) ventilation, chronic NIV has a beneficial effect on other factors that improve respiratory symptoms and HRQoL (figure 3). However, it is not correct to conclude that the improvement in gas exchange is responsible for all of the clinically relevant improvements achieved, as the relationship between gas exchange parameters and HRQoL for example is very limited. Effects such as improvement in sleep quality and sputum clearance, and a reduction in exacerbation rate probably all act positively on HRQoL $[40,65,66]$.

\section{Potential negative factors}

There has been an extensive discussion about patient comfort with HI-NIV and many caregivers feel they should lower settings once patients experience discomfort. Despite this, studies have shown that compliance was better with effective high-intensity settings as compared to ineffective low-intensity settings [17], while

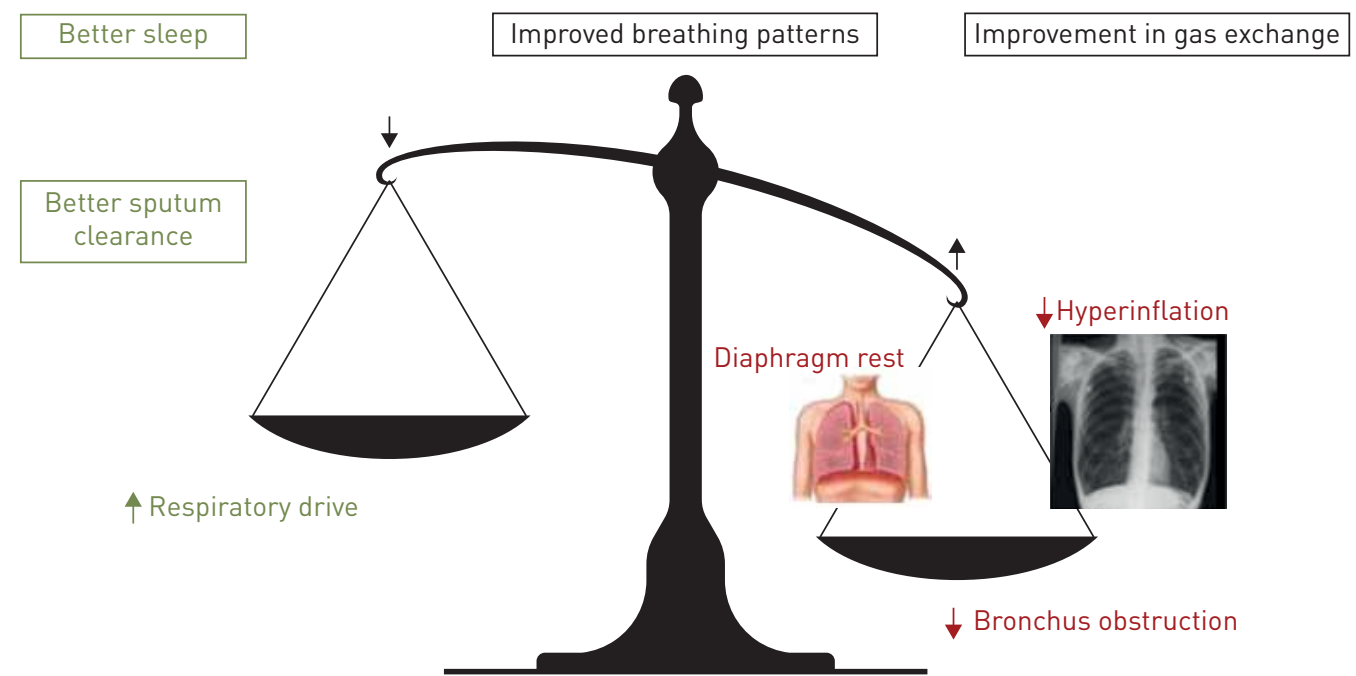

FIGURE 3 The influence of noninvasive ventilation (NIV) on the delicate balance between increased load and decreased capacity of the respiratory system in severe chronic obstructive pulmonary disease (COPD). The radiography image is reproduced from Radiology Assistant (www.radiologyassistant.nl) with permission. 
sleep quality was not worse with HI-NIV [30]. Even the volume-assured settings promoted for comfort did not provide better comfort and tolerance, nor did they provide physiological benefits [67-70]. On the other hand, the time patients need to get used to the high-intensity setting is increased as compared to the "old" low-intensity setting [17, 32]. Improvements in our capability to monitor patients adequately might improve the initiation process, for example by monitoring of patients work of breathing, respiratory events and patient-ventilator asynchrony. For hospital care this might lead to a significant shortening of the hospital stay for NIV initiation and might also help us to initiate patients remotely at home.

A substantial proportion of COPD patients have cardiac comorbidities and we should be aware of the potentially negative effects of HI-NIV on the heart in such cases. The effects of mechanical ventilation on cardiac function are diverse and might result in both positive and negative clinical outcomes [71]. It is known that HI-NIV might reduce cardiac output [72] and, in a small purely physiological study, LuKACSOviTs et al. [73] showed that a setting with a mean IPAP of $28 \mathrm{cmH}_{2} \mathrm{O}$ decreased left ventricular output. However, this study used quite extreme settings and investigated effects only after a short period of NIV, while clinical relevance was not investigated. It has also been shown [32] that if patients use their NIV for a longer period of time, on average, no change in cardiac output or clinical cardiac outcomes (such as N-terminal pro-brain natriuretic peptide (NT-proBNP)) occurs. However, both of these studies were small and this field is surely of interest for future research.

Some caregivers are worried that with HI-NIV the diaphragm is insufficiently unloaded and that diaphragm atrophy will result. It has been shown that even with very high-intensity HI-NIV, with a breathing frequency above the patients' own, patients still trigger the ventilator substantially [74]. Furthermore, patients use their ventilator intermittently, so that periods of spontaneous breathing with high diaphragm loading remain. Also, studies that tested respiratory muscle strength did not show a deterioration that might be an indication of diaphragm atrophy [37].

Another issue that requires attention is that in clinical practice a substantial proportion of COPD patients on HI-NIV experience deventilation dyspnoea, a feeling of severe dyspnoea after being disconnected from the ventilator. This phenomenon has been investigated only in a limited fashion and questions remain as to whether this is a consequence of a forced change in breathing patterns after switching off from the ventilator, the respiratory muscles taking over from a situation of almost controlled ventilation, or a substantial extra degree of hyperinflation induced by a too limited expiratory time for the volume inhaled (especially when the BURR is high) [75]. One small study has shown that if you adjust ventilator settings on polysomnographic titration, in this case leading mainly to a decrease in IPAP, deventilation dyspnoea also decreases [76]. However, it is still not known which mechanisms cause the dyspnoea and exactly which changes occur when you adjust ventilator settings in such a dedicated way.

\section{Initiation of high-intensity noninvasive ventilation}

Initiating and following patients on chronic NIV at home may be a very attractive option both for patients and the healthcare system. Rapidly evolving techniques of telemedicine assist in the transfer of more care from the hospital to the home. However, while these techniques provide us with extensive capabilities to monitor patients, studies on the follow-up of chronic hypercapnic patients on home NIV have given ambiguous results with respect to a reduction in exacerbations and rehospitalisations, as well as to HRQoL [77-79]. Several aspects, such as the content of the telemedicine intervention (what are important data to measure and collect, and how are the results managed etc), the set-up of the healthcare service (how do healthcare professionals act upon results) and geographical differences can influence the effects that telemedicine can provide [80]. Too much monitoring without a thorough self-management plan might cause over reliance on healthcare professionals and an increase in healthcare utilisation instead of a decrease [77]. This emphasises the need for a proper selection of the setting for telemedicine: do you want to transfer in-hospital care to "at least as good" home care, or add care to the standard which should, in that case, improve outcomes? Initiation of home NIV, which is now regularly done during a hospital admission, is an example of care that might be transferred to the home situation. In two well-designed RCTs, it was shown that home initiation of NIV is as good as in-hospital initiation in patients with neuromuscular disease or restrictive thoracic disorders $[81,82]$. In COPD, some of the old RCTs initiated their patients at home [12] but they used LI-NIV and home monitoring, and guidance was very limited or not available. When we initiate patients on HI-NIV, careful monitoring is a must have. Fortunately, technology is evolving and allows us to use remote monitoring for an almost unlimited number of parameters (such as transcutaneous gas exchange measures, ventilator data and patient-ventilator asynchrony), to save data on online platforms or view it on a real-time basis, and to use these data to assist us in decision making and the remote adjustment of ventilator settings. Although the handling of these extensive data provides us with new challenges, for the initiation period their integration might be very helpful and provide clues to success. 


\section{Conclusions}

Several good quality RCTs have shown that if adequate ventilatory settings are applied, aimed at a substantial reduction in $\mathrm{PaCO}_{2}$, then chronic NIV improves outcomes in patients with severe CHRF. An impressive survival benefit was shown; however, outcomes can be further improved once we increase our knowledge about which patients will potentially benefit and how exactly NIV works on the respiratory and non-respiratory system. In this way we are able to adjust our settings based on mechanism, individual patient characteristics and the presence of comorbidities. Although this seems rather complex, the goal should be to develop a treatment algorithm which can easily guide treatment and could as well be applied at home. If the expectation is that the number of COPD patients with an indication for chronic NIV will continue to rise and that patients' preferences are usually for care in the home setting, then home initiation and monitoring of chronic NIV will be the future.

\section{Lessons for clinicians}

Duiverman has helpfully clarified what we have learnt about long-term noninvasive ventilation (NIV) in chronic obstructive pulmonary disease (COPD) over the last few decades. The take home points are:

- NIV achieves benefits in COPD patients with persistent hypercapnia.

- Control of arterial carbon dioxide tension $\left(\mathrm{PaCO}_{2}\right)$ is a key target and high-intensity NIV is an effective way to achieve this.

- NIV is a cost effective therapy, as early results from the HOT-HMV study [35] suggest only five chronically hypercapnic COPD patients need to be treated with NIV to avoid one death.

However, organisational effort will be required to follow-up with patients who are hypercapnic 2 weeks or more after an acute exacerbation and institute therapy. In addition, we need to know more on several fronts:

- If quality of life (QoL) is improved (and here results are mixed)-for how long?

- How does home NIV affect the very end-stage of COPD?

- Symptom palliation with NIV can be valuable but should NIV be withdrawn at the end-of-life: what are our patients' views on this?

Long-term NIV in COPD is a story to be continued!

Anita K. Simonds, Chief Editor

\section{Acknowledgements}

The author would like to thank P.J. Wijkstra (University Medical Center Groningen, University of Groningen, Groningen, The Netherlands) for his valuable comments on the final manuscript.

\section{References}

1 Global Strategy for the Diagnosis, Management and Prevention of COPD, Global Initiative for Chronic Obstructive Lung Disease (GOLD), 2017. http://goldcopd.org/gold-2017-global-strategy-diagnosis-managementprevention-copd/ Date last accessed: February 09, 2018.

2 Leger P, Bedicam JM, Cornette A, et al. Nasal intermittent positive pressure ventilation. Long-term follow-up in patients with severe chronic respiratory insufficiency. Chest 1994; 105: 100-105.

3 Simonds AK, Elliott MW. Outcome of domiciliary nasal intermittent positive pressure ventilation in restrictive and obstructive disorders. Thorax 1995; 50: 604-609.

$4 \quad$ Simonds AK. Home ventilation. Eur Respir J 2003; 22: Suppl. 47, 38s-46s.

5 Casanova C, Celli BR, Tost L, et al. Long-term controlled trial of nocturnal nasal positive pressure ventilation in patients with severe COPD. Chest 2000; 118: 1582-1590.

6 Clini E, Sturani C, Rossi A, et al. The Italian multicentre study on noninvasive ventilation in chronic obstructive pulmonary disease patients. Eur Respir J 2002; 20: 529-538.

7 Diaz O, Begin P, Andresen M, et al. Physiological and clinical effects of diurnal noninvasive ventilation in hypercapnic COPD. Eur Respir J 2005; 26: 1016-1023.

8 Lin CC. Comparison between nocturnal nasal positive pressure ventilation combined with oxygen therapy and oxygen monotherapy in patients with severe COPD. Am J Respir Crit Care Med 1996; 154: 353-358.

9 McEvoy RD, Pierce RJ, Hillman D, et al. Nocturnal non-invasive nasal ventilation in stable hypercapnic COPD: a randomised controlled trial. Thorax 2009; 64: 561-566.

10 Meecham Jones DJ, Paul EA, Jones PW, et al. Nasal pressure support ventilation plus oxygen compared with oxygen therapy alone in hypercapnic COPD. Am J Respir Crit Care Med 1995; 152: 538-544.

11 Struik FM, Lacasse Y, Goldstein RS, et al. Nocturnal noninvasive positive pressure ventilation in stable COPD: a systematic review and individual patient data meta-analysis. Respir Med 2014; 108: 329-337.

12 Strumpf DA, Millman RP, Carlisle CC, et al. Nocturnal positive-pressure ventilation via nasal mask in patients with severe chronic obstructive pulmonary disease. Am Rev Respir Dis 1991; 144: 1234-1239.

13 Gay PC, Patel AM, Viggiano RW, et al. Nocturnal nasal ventilation for treatment of patients with hypercapnic respiratory failure. Mayo Clin Proc 1991; 66: 695-703. 
14 Garrod R, Mikelsons C, Paul EA, et al. Randomized controlled trial of domiciliary noninvasive positive pressure ventilation and physical training in severe chronic obstructive pulmonary disease. Am J Respir Crit Care Med 2000; 162: 1335-1341.

15 Renston JP, DiMarco AF, Supinski GS. Respiratory muscle rest using nasal BiPAP ventilation in patients with stable severe COPD. Chest 1994; 105: 1053-1060.

16 Crimi C, Noto A, Princi P, et al. Domiciliary non-invasive ventilation in COPD: an international survey of indications and practices. COPD 2016; 13: 483-490.

17 Dreher M, Storre JH, Schmoor C, et al. High-intensity versus low-intensity non-invasive ventilation in patients with stable hypercapnic COPD: a randomised crossover trial. Thorax 2010; 65: 303-308.

18 Windisch W, Vogel M, Sorichter S, et al. Normocapnia during nIPPV in chronic hypercapnic COPD reduces subsequent spontaneous PaCO2. Respir Med 2002; 96: 572-579.

19 Windisch W, Kostic S, Dreher M, et al. Outcome of patients with stable COPD receiving controlled noninvasive positive pressure ventilation aimed at a maximal reduction of $\mathrm{Pa}(\mathrm{CO} 2)$. Chest 2005; 128: 657-662.

20 Windisch W, Dreher M, Storre JH, et al. Nocturnal non-invasive positive pressure ventilation: physiological effects on spontaneous breathing. Respir Physiol Neurobiol 2006; 150: 251-260.

21 Celli B, Lee H, Criner G, et al. Controlled trial of external negative pressure ventilation in patients with severe chronic airflow obstruction. Am Rev Respir Dis 1989; 140: 1251-1256.

22 Gigliotti F, Duranti R, Fabiani A, et al. Suppression of ventilatory muscle activity in healthy subjects and COPD patients with negative pressure ventilation. Chest 1991; 99: 1186-1192.

23 Gigliotti F, Spinelli A, Duranti R, et al. Four-week negative pressure ventilation improves respiratory function in severe hypercapnic COPD patients. Chest 1994; 105: 87-94.

24 Goti P, Duranti R, Spinelli A, et al. Effects of the iron lung on respiratory function in chronic hypercapnic COPD patients. Monaldi Arch Chest Dis 1995; 50: 427-432.

25 Gutierrez M, Beroiza T, Contreras G, et al. Weekly cuirass ventilation improves blood gases and inspiratory muscle strength in patients with chronic air-flow limitation and hypercarbia. Am Rev Respir Dis 1988; 138: 617-623.

26 Scano G, Gigliotti F, Duranti R, et al. Changes in ventilatory muscle function with negative pressure ventilation in patients with severe COPD. Chest 1990; 97: 322-327.

27 Shapiro SH, Ernst P, Gray-Donald K, et al. Effect of negative pressure ventilation in severe chronic obstructive pulmonary disease. Lancet 1992; 340: 1425-1429.

28 Zibrak JD, Hill NS, Federman EC, et al. Evaluation of intermittent long-term negative-pressure ventilation in patients with severe chronic obstructive pulmonary disease. Am Rev Respir Dis 1988; 138: 1515-1518.

29 Windisch W, Storre JH, Kohnlein T. Nocturnal non-invasive positive pressure ventilation for COPD. Expert Rev Respir Med 2015; 9: 295-308.

30 Dreher M, Ekkernkamp E, Walterspacher S, et al. Noninvasive ventilation in COPD: impact of inspiratory pressure levels on sleep quality. Chest 2011; 140: 939-945.

31 Schwarz SB, Magnet FS, Windisch W. Impact of home mechanical ventilation on sleep quality. Curr Opin Pulm Med 2017; 23: 500-505.

32 Duiverman ML, Maagh P, Magnet FS, et al. Impact of high-intensity-NIV on the heart in stable COPD: a randomised cross-over pilot study. Respir Res 2017; 18: 76.

33 Duiverman ML, Wempe JB, Bladder G, et al. Two-year home-based nocturnal noninvasive ventilation added to rehabilitation in chronic obstructive pulmonary disease patients: a randomized controlled trial. Respir Res 2011 12: 112 .

34 Kohnlein T, Windisch W, Kohler D, et al. Non-invasive positive pressure ventilation for the treatment of severe stable chronic obstructive pulmonary disease: a prospective, multicentre, randomised, controlled clinical trial. Lancet Respir Med 2014; 2: 698-705.

35 Murphy PB, Rehal S, Arbane G, et al. Effect of home noninvasive ventilation with oxygen therapy vs oxygen therapy alone on hospital readmission or death after an acute COPD exacerbation: a randomized clinical trial. JAMA 2017; 317: 2177-2186.

36 Struik FM, Sprooten RT, Kerstjens HA, et al. Nocturnal non-invasive ventilation in COPD patients with prolonged hypercapnia after ventilatory support for acute respiratory failure: a randomised, controlled, parallel-group study. Thorax 2014; 69: 826-834.

37 Duiverman ML, Wempe JB, Bladder G, et al. Nocturnal non-invasive ventilation in addition to rehabilitation in hypercapnic patients with COPD. Thorax 2008; 63: 1052-1057.

38 Titlestad IL, Lassen AT, Vestbo J. Long-term survival for COPD patients receiving noninvasive ventilation for acute respiratory failure. Int J Chron Obstruct Pulmon Dis 2013; 8: 215-219.

39 Chu CM, Chan VL, Lin AW, et al. Readmission rates and life threatening events in COPD survivors treated with non-invasive ventilation for acute hypercapnic respiratory failure. Thorax 2004; 59: 1020-1025.

40 Niewoehner DE. The impact of severe exacerbations on quality of life and the clinical course of chronic obstructive pulmonary disease. Am J Med 2006; 119: 38-45.

41 McGhan R, Radcliff T, Fish R, et al. Predictors of rehospitalization and death after a severe exacerbation of COPD. Chest 2007; 132: 1748-1755.

42 Suissa S, Dell'Aniello S, Ernst P. Long-term natural history of chronic obstructive pulmonary disease: severe exacerbations and mortality. Thorax 2012; 67: 957-963.

43 Murphy PB, Zoumot Z, Polkey MI. Noninvasive ventilation and lung volume reduction. Clin Chest Med 2014; 35: 251-269.

44 Cano NJ, Pichard C, Court-Fortune I, et al. Survival of patients with chronic respiratory failure on long-term oxygen therapy and or non-invasive ventilation at home. Clin Nutr 2015; 34: 739-744.

45 Aida A, Miyamoto K, Nishimura M, et al. Prognostic value of hypercapnia in patients with chronic respiratory failure during long-term oxygen therapy. Am J Respir Crit Care Med 1998; 158: 188-193.

46 Budweiser S, Jorres RA, Riedl T, et al. Predictors of survival in COPD patients with chronic hypercapnic respiratory failure receiving noninvasive home ventilation. Chest 2007; 131: 1650-1658.

47 Oga T, Taniguchi H, Kita H, et al. Analysis of the relationship between health status and mortality in hypercapnic patients with noninvasive ventilation. Clin Respir J 2017; 11: 772-780. 

COPD: mechanisms underlying changes in arterial blood gas tensions. Eur Respir J 1991; 4: 1044-1052.

49 Nickol AH, Hart N, Hopkinson NS, et al. Mechanisms of improvement of respiratory failure in patients with COPD treated with NIV. Int J Chron Obstruct Pulmon Dis 2008; 3: 453-462.

50 Diaz O, Begin P, Torrealba B, et al. Effects of noninvasive ventilation on lung hyperinflation in stable hypercapnic COPD. Eur Respir J 2002; 20: 1490-1498.

51 Noble PB, Pascoe CD, Lan B, et al. Airway smooth muscle in asthma: linking contraction and mechanotransduction to disease pathogenesis and remodelling. Pulm Pharmacol Ther 2014; 29: 96-107.

52 Gosens R, Grainge C. Bronchoconstriction and airway biology: potential impact and therapeutic opportunities. Chest 2015; 147: 798-803.

53 Grainge CL, Lau LC, Ward JA, et al. Effect of bronchoconstriction on airway remodeling in asthma. $N$ Engl J Med 2011; 364: 2006-2015.

54 Kistemaker LE, Slebos DJ, Meurs H, et al. Anti-inflammatory effects of targeted lung denervation in patients with COPD. Eur Respir J 2015; 46: 1489-1492.

55 De Backer L, Vos W, Dieriks B, et al. The effects of long-term noninvasive ventilation in hypercapnic COPD patients: a randomized controlled pilot study. Int J Chron Obstruct Pulmon Dis 2011; 6: 615-624.

56 Hajian B, De Backer J, Sneyers C, et al. Pathophysiological mechanism of long-term noninvasive ventilation in stable hypercapnic patients with COPD using functional respiratory imaging. Int J Chron Obstruct Pulmon Dis 2017; 12: 2197-2205.

57 Rochester DF, Arora NS. Respiratory muscle failure. Med Clin North Am 1983; 67: 573-597.

58 Gorini M, Misuri G, Corrado A, et al. Breathing pattern and carbon dioxide retention in severe chronic obstructive pulmonary disease. Thorax 1996; 51: 677-683.

59 Grassino A, Bellemare F, Laporta D. Diaphragm fatigue and the strategy of breathing in COPD. Chest 1984; 85 51S-54S.

60 Montes de Oca M, Celli BR. Respiratory muscle recruitment and exercise performance in eucapnic and hypercapnic severe chronic obstructive pulmonary disease. Am J Respir Crit Care Med 2000; 161: 880-885.

61 Ottenheijm CA, Heunks LM, Dekhuijzen RP. Diaphragm adaptations in patients with COPD. Respir Res 2008; 9: 12.

62 Levine S, Kaiser L, Leferovich J, et al. Cellular adaptations in the diaphragm in chronic obstructive pulmonary disease. N Engl J Med 1997; 337: 1799-1806.

63 Schonhofer B, Polkey MI, Suchi S, et al. Effect of home mechanical ventilation on inspiratory muscle strength in COPD. Chest 2006; 130: 1834-1838.

64 Duiverman ML, Struik FM, Wijkstra PJ. Noninvasive ventilation in severe stable COPD: is it effective, and if so, in what way? Eur Respir J 2008; 31: 1136-1137. Reply from the authors pp. 1137.

65 Akinci B, Aslan GK, Kiyan E. Sleep quality and quality of life in patients with moderate to very severe chronic obstructive pulmonary disease. Clin Respir J 2017; in press [https://doi.org/10.1111/cri.12738].

66 Eslaminejad A, Safa M, Ghassem Boroujerdi F, et al. Relationship between sleep quality and mental health according to demographics of 850 patients with chronic obstructive pulmonary disease. J Health Psychol 2017; 22 : 1603-1613.

67 Oscroft NS, Ali M, Gulati A, et al. A randomised crossover trial comparing volume assured and pressure preset noninvasive ventilation in stable hypercapnic COPD. COPD 2010; 7: 398-403.

68 Storre JH, Matrosovich E, Ekkernkamp E, et al. Home mechanical ventilation for COPD: high-intensity versus target volume noninvasive ventilation. Respir Care 2014; 59: 1389-1397.

69 Ekkernkamp E, Storre JH, Windisch W, et al. Impact of intelligent volume-assured pressure support on sleep quality in stable hypercapnic chronic obstructive pulmonary disease patients: a randomized, crossover study. Respiration 2014; 88: 270-276.

70 Ekkernkamp E, Kabitz HJ, Walker DJ, et al. Minute ventilation during spontaneous breathing, high-intensity noninvasive positive pressure ventilation and intelligent volume assured pressure support in hypercapnic COPD COPD 2014; 11: 52-58

71 Duiverman ML, Arellano-Maric MP, Windisch W. Long-term noninvasive ventilation in patients with chronic hypercapnic respiratory failure: assisting the diaphragm, but threatening the heart? Curr Opin Pulm Med 2016; 22: $130-137$.

72 Cournand A, Motley HL. Physiological studies of the effects of intermittent positive pressure breathing on cardiac output in man. Am J Physiol 1948; 152: 162-174.

73 Lukacsovits J, Carlucci A, Hill N, et al. Physiological changes during low- and high-intensity noninvasive ventilation. Eur Respir J 2012; 39: 869-875.

74 Duiverman ML, Huberts AS, van Eykern LA, et al. Respiratory muscle activity and patient-ventilator asynchrony during different settings of noninvasive ventilation in stable hypercapnic COPD: does high inspiratory pressure lead to respiratory muscle unloading? Int J Chron Obstruct Pulmon Dis 2017; 12: 243-257.

75 Esquinas AM, Ucar ZZ, Kirakli C. Deventilation syndrome in severe COPD patients during long-term noninvasive mechanical ventilation: poor sleep pattern, hyperinflation, or silent chronic muscular fatigue? Sleep Breath 2014 18: 225-226

76 Adler D, Perrig S, Takahashi H, et al. Polysomnography in stable COPD under non-invasive ventilation to reduce patient-ventilator asynchrony and morning breathlessness. Sleep Breath 2012; 16: 1081-1090.

77 Chatwin M, Hawkins G, Panicchia L, et al. Randomised crossover trial of telemonitoring in chronic respiratory patients (TeleCRAFT trial). Thorax 2016; 71: 305-311.

78 Vitacca M, Bianchi L, Guerra A, et al. Tele-assistance in chronic respiratory failure patients: a randomised clinical trial. Eur Respir J 2009; 33: 411-418.

79 Bertini S, Picariello M, Gorini M, et al. Telemonitoring in chronic ventilatory failure: a new model of survellaince, a pilot study. Monaldi Arch Chest Dis 2012; 77: 57-66.

80 Ambrosino N, Vitacca M, Dreher M, et al. Tele-monitoring of ventilator-dependent patients: a European Respiratory Society statement. Eur Respir J 2016; 48: 648-663.

81 Hazenberg A, Kerstjens HA, Prins SC, et al. Initiation of home mechanical ventilation at home: a randomised controlled trial of efficacy, feasibility and costs. Respir Med 2014; 108: 1387-1395.

82 Chatwin M, Nickol AH, Morrell MJ, et al. Randomised trial of inpatient versus outpatient initiation of home mechanical ventilation in patients with nocturnal hypoventilation. Respir Med 2008; 102: 1528-1535. 